\title{
Cutting force and chip formation in end milling operation when machining nickel- based superalloy, Hastelloy C-2000
}

\author{
N.H. Razak ${ }^{1}$, M.M. Rahman ${ }^{2,3 *}$, and K. Kadirgama ${ }^{2}$ \\ ${ }^{1}$ Faculty of Manufacturing Engineering, Universiti Malaysia Pahang \\ 26600 Pekan, Pahang, Malaysia \\ email: mustafizur@ump.edu.my \\ ${ }^{2}$ Faculty of Mechanical Engineering, Universiti Malaysia Pahang \\ 26600 Pekan, Pahang, Malaysia \\ email: mustafizur@ump.edu.my \\ ${ }^{3}$ Automotive Engineering Centre, Universiti Malaysia Pahang \\ 26600 Pekan, Pahang, Malaysia
}

\begin{abstract}
This paper presents an experimental study of the cutting force and chip formation in the end milling of the nickel-based superalloy, Hastelloy C-2000. The experiment was conducted using two different cutting inserts under wet conditions - namely physical vapor deposition coated with TiAlN, and uncoated carbide. The assessment of machining performance is based on a design of experiment. New insight into the influence of the cutting process on the cutting force and chip formation are key measures of machining performance. The effect of the machining parameters on chip formation was examined through scanning electron microscope micrographs and energy dispersive x-ray tests. The cutting forces and chip formation analysis for different sets of experiments were examined and compared in order to establish the most suitable cutting conditions, through highlighting the drawbacks and by suggesting proper measures to be undertaken during machining performance, which might overcome the barriers of machining Hastelloy C2000 .
\end{abstract}

Keywords: Cutting force; chip formation; Hastlelloy C-2000; coated carbide; uncoated carbide.

\section{INTRODUCTION}

Nickel-based alloys (Ni-Co-Cr, Ni-Fe-Cr or Ni-Co-Fe) are very popular in the industry owing to their advantages over titanium-based alloys [1-3]. The main strengths of nickelbased alloys are heat resistance, retaining their high mechanical and chemical properties at high temperatures, and having high melting temperatures, high corrosion resistance, as well as resistance to thermal fatigue, thermal shock, creep, and erosion [4-6]. Nickelbased alloys have the ability to retain most of their strength, even after long exposure to extremely high temperatures and are the only material suitable for turbine sections of jet engines. Nickel-based super alloys have some characteristics that are responsible for their poor machinability $[6,7]$. They have an austenitic matrix, and as with stainless steels, they work harden rapidly during machining. Moreover, localization of shear in the chip produces abrasive saw-toothed edges, which make swarf handling difficult. These alloys also have a tendency to weld with the tool material at the high temperatures generated 
during machining. The tendencies to form a built up edge and the presence of hard abrasive carbides in their microstructure are also problems associated with machinability. As machining is a finishing process with specified dimensions, tolerances and surface finish, the type of surface that a machining operation generates and its characteristics are of great importance in manufacturing [8-12]. Properly optimizing the machining factors by consideration of the machinability criteria, such as low cutting forces, surface finish, tool life, power consumption, and dimensional accuracy, production rates and excellent output can be obtained with conventional machining methods, if the unique characteristics of this metal are taken into account [13-18]. According to Fang and $\mathrm{Wu}$ [19], when the cutting conditions are the same, the cutting force and the thrust force in machining Inconel 718 are higher compared with those in the machining of Ti-6Al-4V. Because of the property of hardening possessed by nickel-based alloy, machining becomes difficult as soon as the milling cutter is used and consequently, the metal is not cut but pushed, because the cutting edge is not very sharp and ultimately, the cutting force and temperature increase [20]. Traditionally, the softening of the workpiece material increases with cutting speed while reducing cutting forces to the minimum [21, 22]. Chip formation refers to the formation of chips in the primary and secondary deformation zones. The cutting forces and contact processes at the tool-chip interface are among the basic points of consideration in the kinematic relationship. Attention was primarily focused on the kinematic relationships, cutting force and contact process at the tool-tip interface; however, later on, the chip-breaking problem became increasingly important with increasing cutting speeds and the development of new materials that are difficult to machine $[23,24]$. The modern sense of this term implies that the chip, which just left the tool-chip interface, has yet to be broken $[25,26]$. Carbide cutting tools are amongst the oldest of the hard cutting tools. The use of coated and uncoated tungsten carbide (WC) cutting tools is seen to offer control over the residual stress, because the coated WC cutting tool enhances the residual field on the machined workpiece, reducing the cutting temperature when machining nickel-based alloy [27-29]. However, it was still observed that uncoated tools reach higher maximum process temperatures than coated tools [27, 30]. When using coated carbide tools, it was found that lower maximum tool temperature, surface stresses, and smoother chip formation could be observed for steel workpieces, which could be effective in white layer formation, residual stresses, and thickness of the work-hardened zone. Ezugwu et al. [31] reported that multi-layer physical vapor deposition (PVD)-coated carbide tools gave better tool life performance than single-layer PVD-coated carbide tools, as well as multi-layer chemical vapor deposition (CVD)coated tools, during the turning of IN-718, mostly because they have higher hardness, toughness, abrasion resistance, and good heat transmission behavior. Jindal et al. [32] stated that at both speeds, TiAlN- and TiCN-coated tools performed significantly better than tools with TiN coatings. TiAIN performed well compared with $\mathrm{CrN}$ because it is harder and more able to resist oxidation. The aims of this paper are to investigate the cutting force and chip formation of the end milling operation when machining Hastelloy C-2000 using uncoated carbide and coated carbide inserts.

\section{METHODS AND MATERIALS}

\section{Experiment Details}

Design of experiment (DOE) is used to reduce the number of experiments and time. The study uses the Box-Behnken design because it has fewer design points and is less expensive to run than central composite designs with the same number of factors. Three 
levels of cutting parameters were selected to investigate the machinability of this alloy. These included the feed rate range for the Hastelloy C-2000 workpiece: 0.1, 0.15, and 0.2 $\mathrm{mm} /$ tooth, different depths of cut: $0.4,0.7$, and $1.0 \mathrm{~mm}$, and various cutting speeds: 15 , 23 , and $31 \mathrm{~m} / \mathrm{min}$. The selected inputs were chosen based on suggestions from the suppliers of the Hastelloy C-2000 workpiece. Various input parameters used in the experiments is listed in Table 1.

Table 1. Machining parameters and their levels.

\begin{tabular}{lccc}
\hline \multicolumn{1}{c}{ Process } & \multicolumn{3}{c}{ Level } \\
\cline { 2 - 4 } Parameters & -1 & 0 & 1 \\
\hline Feed rate (mm/tooth) & 0.1 & 0.15 & 0.2 \\
Axial depth & 0.4 & 0.7 & 1 \\
Cutting speed (mm/min) & 15 & 23 & 31 \\
\hline
\end{tabular}

The chemical and physical properties of the workpiece material Hastelloy C-2000 are given in Tables 2 and 3, respectively. The relatively high proportions of chromium $(23 \%)$ and molybdenum $(16 \%)$ of the workpiece mean that the material is hard to machine. The nickel content of approximately 50\% makes the alloy suitable for hightemperature applications. The dimensions of the test specimen used in the experiments were $46 \times 120 \times 20 \mathrm{~mm}$. The test block was annealed and has Rockwell B 90 hardness. The experimental study was carried out in wet cutting conditions on a CNC milling machine by slotting machining, equipped with a maximum spindle speed of $4000 \mathrm{rpm}$, feed rate of $5.1 \mathrm{~m} / \mathrm{min}$, and a $5.6-\mathrm{kW}$ drive motor. The cutting tool inserts used to cut the material were uncoated carbide (CTP 1235) and coated carbide (CTW 4615). CTW 4615 is a coated carbide grade with a PVD TiAlN coating with grade designation P35 M50. Titanium-aluminum nitride (TiA1N) is very effective in cutting stainless steels and aerospace alloys. The advantages of hard material layers include the reduction of friction, heat, oxidation, and diffusion. CTP 1235 is an uncoated carbide with grade designation K15. The chemical composition of the workpiece is shown in Table 2. The physical properties of the workpiece are presented in Table 3. The following are the details of the tool geometry of the inserts when mounted on the tool holder: (a) special shape; (b) axial rake angle: $19.5^{\circ}$; radial angle: $5^{\circ}$; and (d) sharp cutting edge. The composition of cutting tool inserts is presented in Table 4. Figure 1 shows the experimental setup and shape of the uncoated carbide inserts: (a) workpiece at CNC milling machine, (b) CNC milling machine, shape of cutting insert, (d) SEM view of uncoated carbide before machining. A Kistler force dynamometer, model 1679A5, was used to record the cutting force during the experimental milling operations. After conducting the first pass (one pass is equal to $120 \mathrm{~mm}$ length) of the 15 cutting experiments, the workpiece was removed from the clamp and chips collected. The sample then underwent the grinding and polishing process before the surface integrity of the workpiece was examined by scanning electron microscope (SEM). SEM with energy dispersive x-ray (EDX) was used to examine the chip formation that resulted from the combination of the machining parameters and to investigate the chemical elements in the chips and machined workpiece. Water-soluble coolant was used for the experiments. Two nozzles were opened fully to directly flush the cutting tool and produce wet cutting. 
Table 2. Chemical composition of workpiece material (Hastelloy C-2000), Haynes International Catalog. [33].

\begin{tabular}{llllllllll}
\hline Composition & $\mathrm{Ni}$ & $\mathrm{Cr}$ & $\mathrm{Mo}$ & $\mathrm{Fe}$ & $\mathrm{Cu}$ & $\mathrm{Al}$ & $\mathrm{Mn}$ & $\mathrm{Si}$ & $\mathrm{C}$ \\
\hline Wt. (\%) & Balance & 23 & 16 & 3 & 1.60 & 0.50 & 0.50 & 0.08 & 0.01 \\
\hline
\end{tabular}

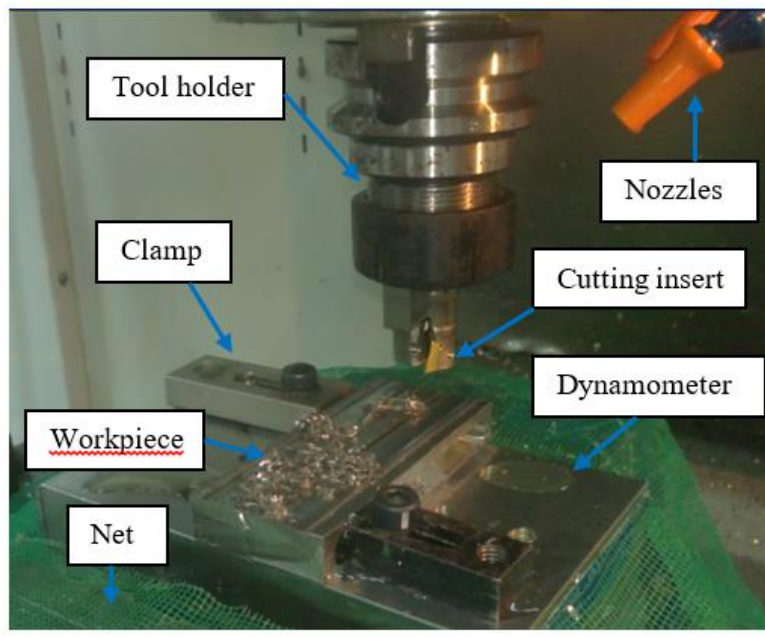

(a) Workpiece at CNC milling machine

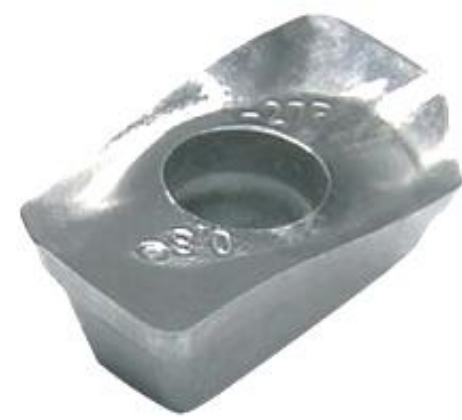

(c) Shape of cutting insert

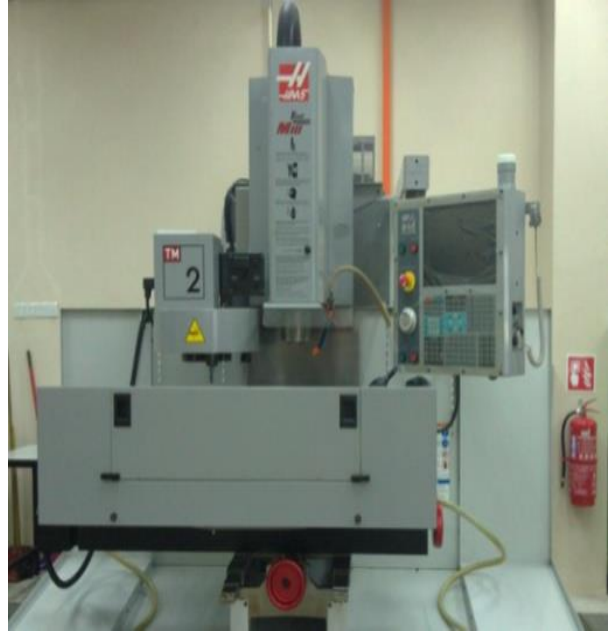

(b) CNC milling machine

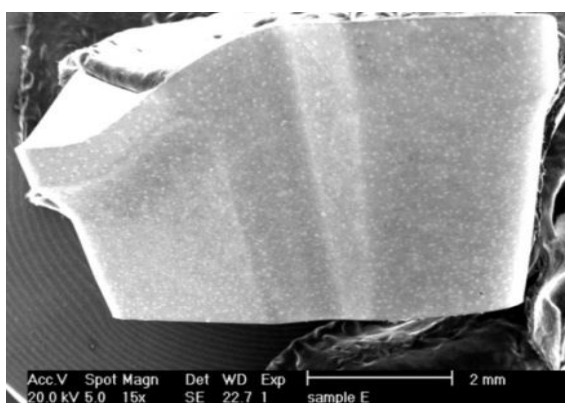

(d) SEM view before machining

Figure 1. The experimental setup and shapes of the uncoated carbide inserts: (a) workpiece at CNC milling machine, (b) CNC milling machine, (c) shape of cutting insert, (d) SEM view of uncoated carbide before machining.

Table 3. Physical properties of workpiece material (Hastelloy C-2000 at room temperature),Haynes International Catalog

\begin{tabular}{lc}
\hline \multicolumn{1}{c}{ Parameters and unit } & Value \\
\hline Density $\left(\mathrm{g} / \mathrm{cm}^{3}\right)$ & 8.5 \\
Thermal conductivity $\left(\mathrm{W} / \mathrm{m}^{\circ} \mathrm{C}\right)$ & 9.1 \\
Mean coefficient of thermal expansion $\left(\mu \mathrm{m} / \mathrm{m}^{\circ} \mathrm{C}\right)$ & 12.4 \\
Thermal Diffusivity $\left(\mathrm{cm}^{2} / \mathrm{s}\right)$ & 0.025 \\
Specific heat $\left(\mathrm{J} / \mathrm{kg}^{\circ} \mathrm{C}\right)$ & 428 \\
Modulus of elasticity $(\mathrm{GPa})$ & 223 \\
\hline
\end{tabular}


Table 4. The composition of the cutting inserts.

\begin{tabular}{cccc}
\hline Code name & Composition & Coating & Grain size \\
\hline CTW 4615 & $6 \%$ Co,4\% carbide,90\% WC & PVD-TiA1N,TiN & $1 \mu \mathrm{m}$ \\
CTP 1235 & $6 \%$ Co, 94 \% WC & - & $4 \mu \mathrm{m}$ \\
\hline
\end{tabular}

\section{RESULTS AND DISCUSSION}

\section{Chip Formation}

Figure 3 shows the shape of the chips and the surface texture at a feed rate of 0.2 $\mathrm{mm} /$ tooth, an axial depth of $0.7 \mathrm{~mm}$, and a cutting speed of $31 \mathrm{~m} / \mathrm{min}$ for coated carbide inserts. This type of chip exhibits much waving and depending on the waviness, chip formation can be organized into two groups: unstable chips and critical chips. Unstable chips point towards adiabatic shear occurring in the worked material. The chatter acts as a cause of uneven surface roughness and the completed surface will comprise alternate unburnished (dull) and burnished (shiny) areas. This mechanism of chip formation differs significantly from that of stable cutting. Chip formation pertains to the formation of the chip in the primary and secondary deformation zones. Primarily, attention was focused towards the kinematic relationships, the cutting force, and the contact process at the tooltip interface. The dilemma of chip breaking became tremendously significant with increasing cutting speeds and the establishment of novel materials that are difficult to machine [34]. The chip formation relies upon the outcome of the workpiece and cutting tool materials, feed rate, cutting speed, and the cutting tool geometry [35]. The contemporary meaning of this expression implies that the chip that has immediately left the tool-chip interface is said to be broken [26]. The chips produced during machining rely upon the materials being machined, the tools, and the cutting condition. The mechanism of chip formation and separation is related to the extreme strain rate that occurs during the machining process. In the case of cutting of Hastelloy C-2000, owing to its lower thermal conductivity characteristics, temperature can be very high locally in some areas of the workpiece, resulting in thermal softening, which reduces the material strain hardening capacity and therefore, shear instability occurs in a narrow band of chips.

When chattering is developed fully, the cutting edge is no longer moving in the way that it does in stable cutting, but instead it vibrates while it is rotating. This is illustrated in Figure 4, in which the chip was generated by uncoated carbide at a cutting machining feed rate of $0.2 \mathrm{~mm} /$ tooth, a depth of cut of $0.7 \mathrm{~mm}$, and a cutting speed of 31 $\mathrm{m} / \mathrm{min}$. The structure of the critical chip is dissimilar to the unstable chips because of the chatter marks. Owing to the lower thermal conductivity features of Hastelloy C-2000, there can be a rise in temperature locally in a few areas of the workpiece, which might result in thermal softening that decreases the material strain hardening capability. Thus, shear unsteadiness occurs in a narrow band of chips. No harsh plastic deformation can be seen in the area of adjacent cracks produced between the constituents of the chip. It was determined that a work material that cracks at a very low cutting speed would not crack at a higher cutting speed, compared with the chip formation at a low cutting speed. The crack increases without any obvious deformation of the workpiece's free surface at a low cutting speed. A compressive stress ahead of the cutting edge was the reason for the formation of the cracks at the free surface, creating the brittleness of the workpiece). The cracks produced during the formation of chips cannot be entirely repaired by plastic deformation [36-38]. Therefore, their tips can be perceived at high magnification. The crack mechanism commences through gross periodic fractures taking place from the 
workpiece's free surface to the cutting tool tip, whereas the fracture initiates at the workpiece surface and extends down the tool tip until the compressive stress established from the tool tip has the propensity to prevent the crack [39].

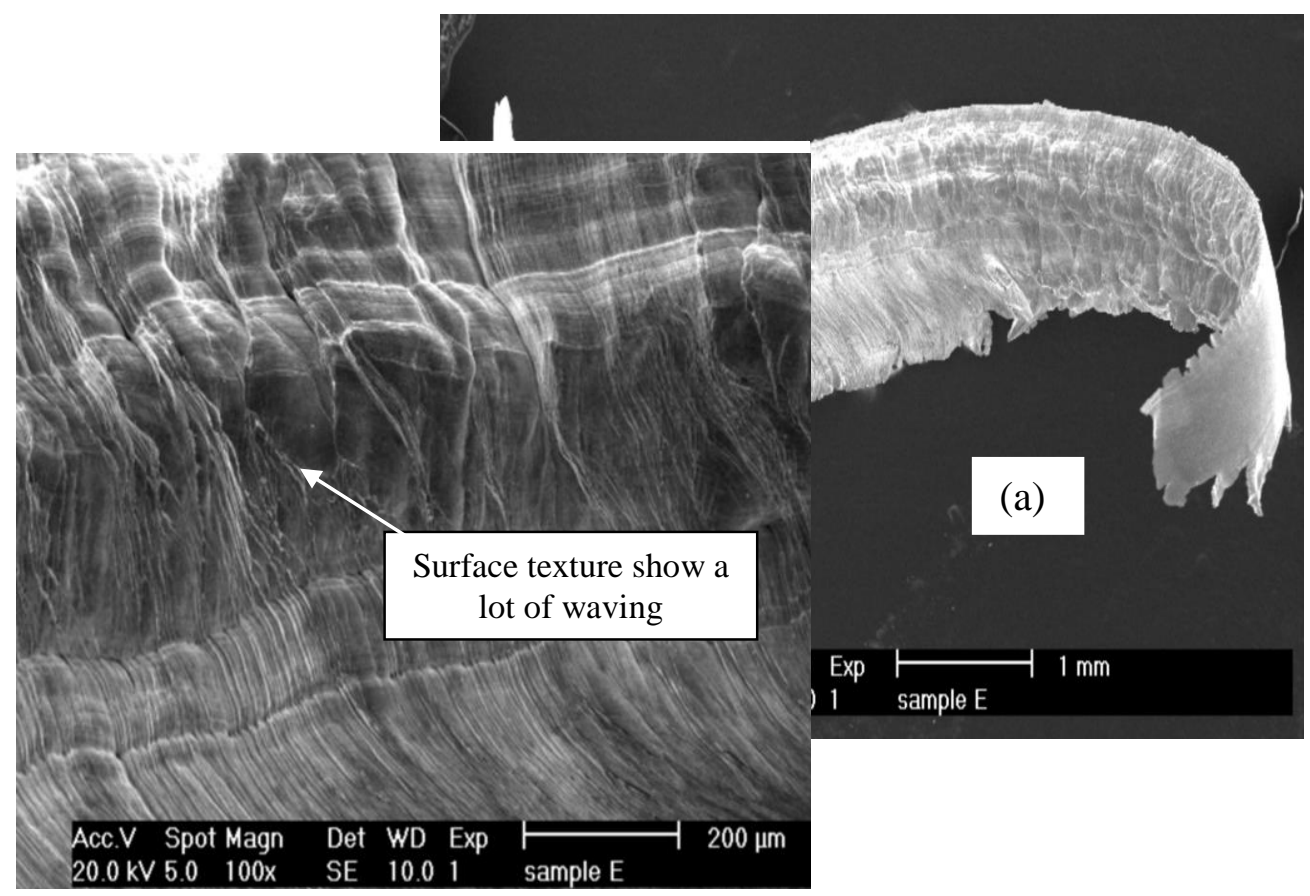

(b)

Figure 3. (a) Shape of chip, (b) Unstable chip - CTW 4615

Figure 5 shows the saw-toothed edge chip. The deformation of the chip is normally known to be inconsistent and deformation is very high in a narrow band between the segments. Abrasive saw-toothed edges are generated from the localization of shear in the chip. The chip is a constant type at low speed cutting and when the speed is enhanced, it changes into a saw-tooth type. This demonstrates that the higher the cutting speed, the more the saw-tooth chips are visible. The mechanism engaged in the creation of sawtooth chips is very intricate and is attributed to adiabatic shear on the shear plane and cycle cracks at the free surface of the chip [40]. There is no regular principle to forecast the onset of saw-tooth chip formation. The creation of saw-tooth chips is attributable to adiabatic shearing and surface crack propagation [5, 41]. Additionally, the catastrophic strain localization and fracture or crack generation contribute to saw-tooth creation [38, 42]. 


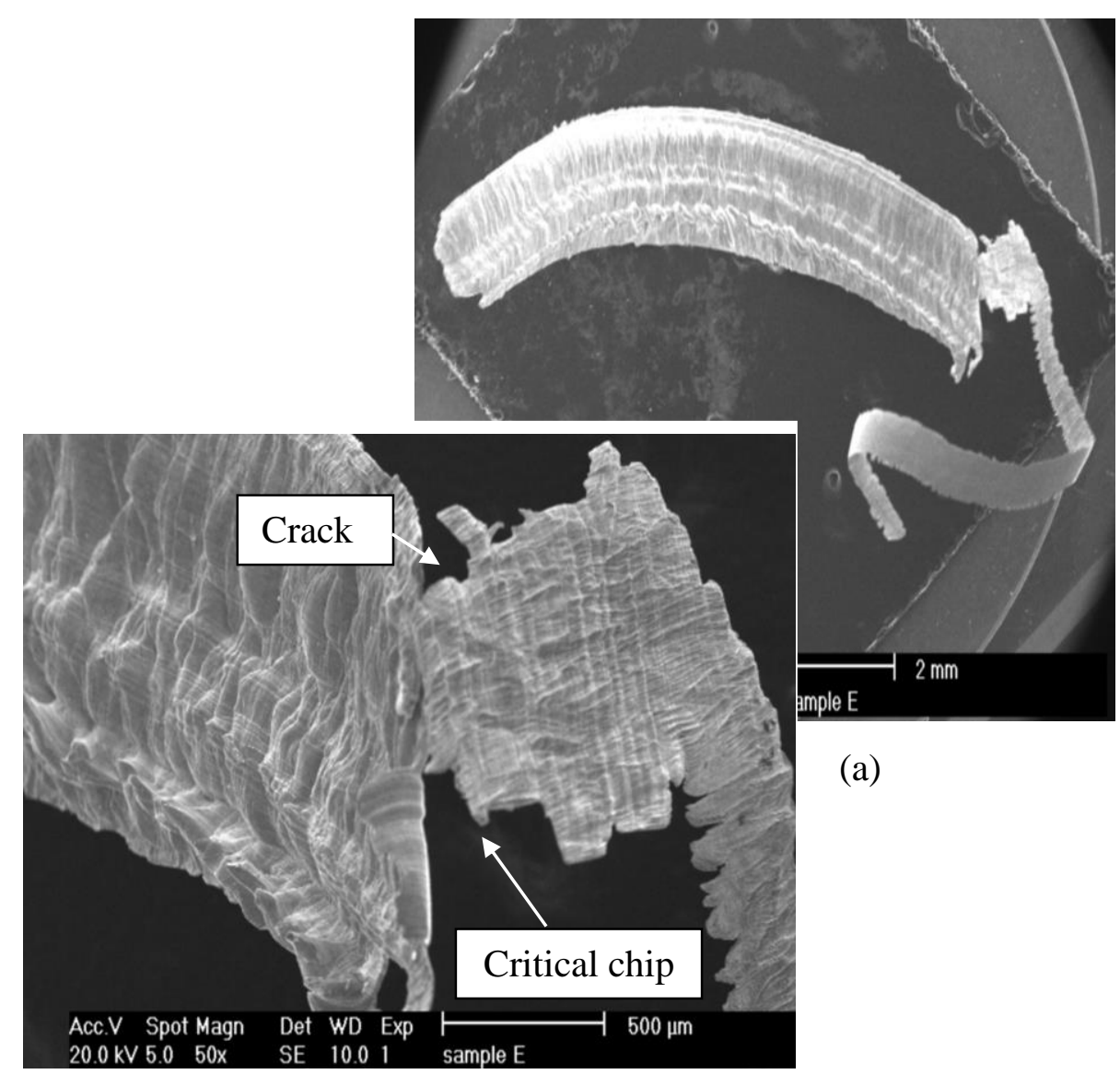

Figure 4. (a) Shape of chip, (b) Critical chip - CTP 1235.

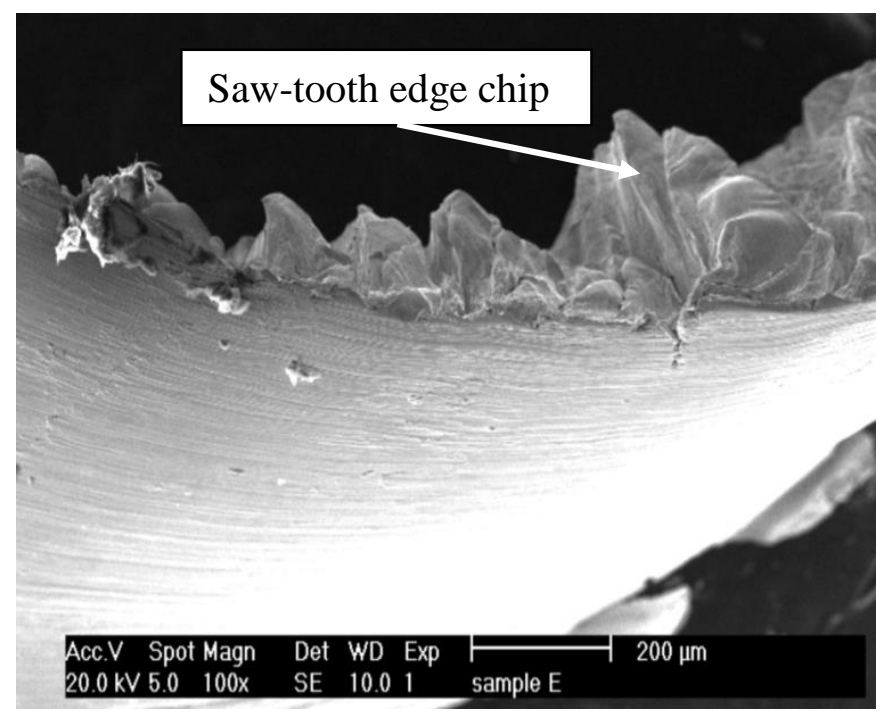

Figure 5. Saw-tooth edge chip

Figure 6 illustrates that a small quantity of chip flows out of the cutting zone throughout the process of machining with coated carbide at machining parameters of: feed rate $0.15 \mathrm{~mm} /$ tooth, axial depth $1.0 \mathrm{~mm}$, and cutting speed $31 \mathrm{~m} / \mathrm{min}$. Many chips are pressed to the sides of the slot, and become piled up piece-wise. The chips welded on both 
the sides of the slot slow the flow of the chip and the cutting temperature rises because the heat produced cannot be dissipated with the chips. Simultaneously, the cutting force increases rapidly. Each and every chip is welded on the sides of the slot, there is no chip disposal and the cutting force is over $620.77 \mathrm{~N}$. Regarding the earlier discussions, it is established that the cutting temperature and chip disposal are very significant, concurrent factors that affect the slot milling of Hastelloy C-2000, because the cutting temperature is associated with the cutting speed. The cutting temperature will be less than the softening point of gamma prime $(\gamma)$ when the speed is low. High cutting speed is disadvantageous because it produces harsh strain hardening of the work material. The work material is softened during cutting at high speed, but the cutting temperature will also be too high for the cutting tool to survive. Owing to these circumstances, the welding of chips on the work surface becomes grave and it is highly undesirable.

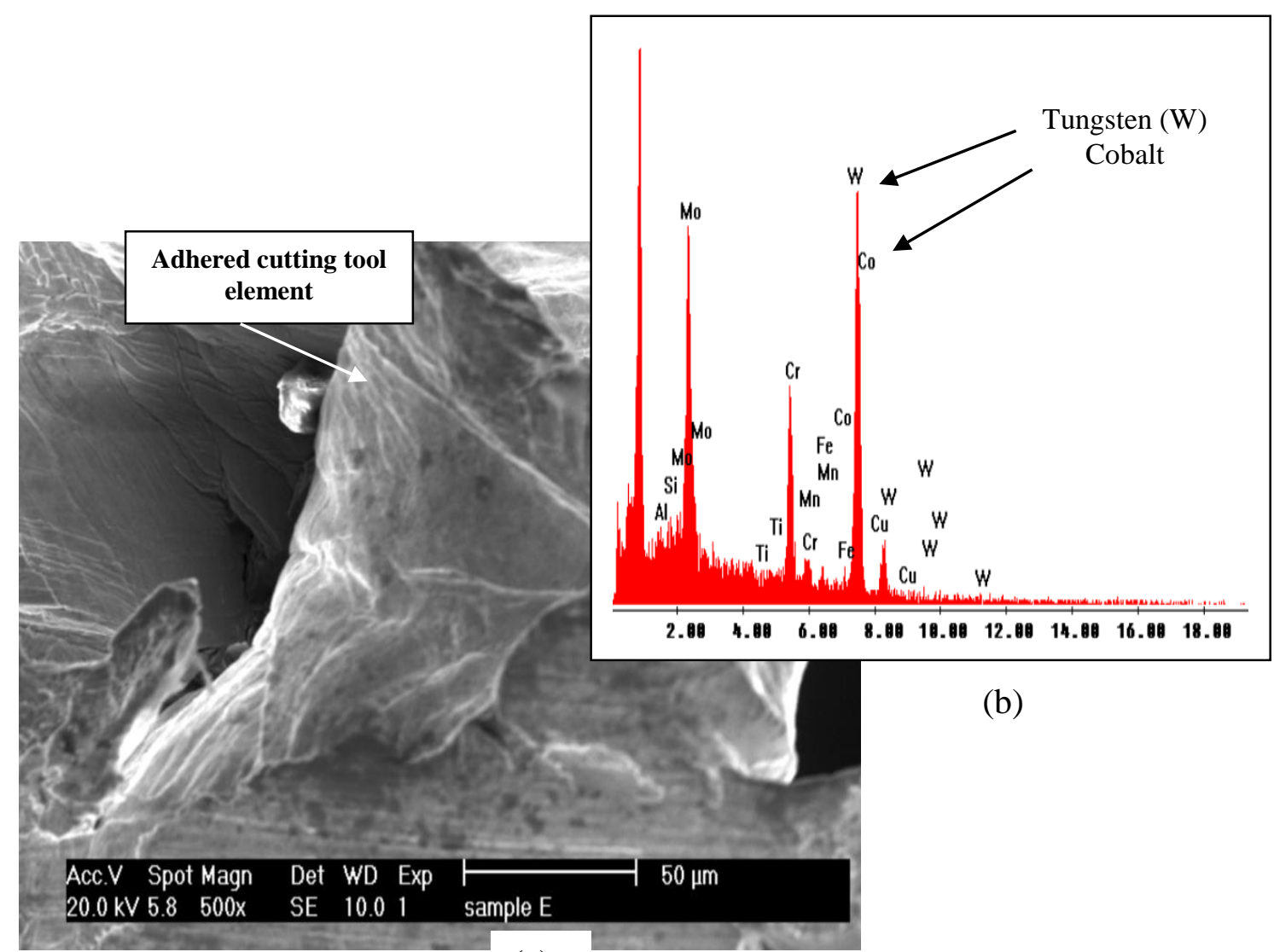

(a)

Figure 6 . The adhesion mechanism with uncoated carbide insert

As shown in Figure 7, only a small amount of chips flows out of the cutting zone during machining with coated carbide (CTW 4615) at machining parameters of: feed rate $0.15 \mathrm{~mm} /$ tooth, axial depth $1.0 \mathrm{~mm}$, and cutting speed $31 \mathrm{~m} / \mathrm{min}$. Most of the chips are pushed to the sides of the slot, and become stacked piece-wise. The chips welded on both sides of the slot retard chip flow and the cutting temperature will increase because the heat generated cannot be dissipated with the chips. At this moment, the cutting force will increase rapidly. All chips are welded onto the sides of the slot and there is no chip disposal. Cutting force is over $620.77 \mathrm{~N}$. According to previous discussions, it is concluded that cutting temperature and chip disposal are two very important and 
correlated factors affecting slot milling of Hastelloy C-2000. Liao et al. (2008) stated that cutting temperature is related to cutting speed. When speed is too low, cutting temperature will be lower than the softening point of $\gamma$. The higher the cutting speed, the more severe the strain hardening of the work material and this is detrimental to cutting. When cutting speed is too high, the work material is softened but the cutting temperature will be too high for the cutting tool to withstand. Under these conditions, the welding of the chips on the work surface becomes very serious, which is highly undesirable.

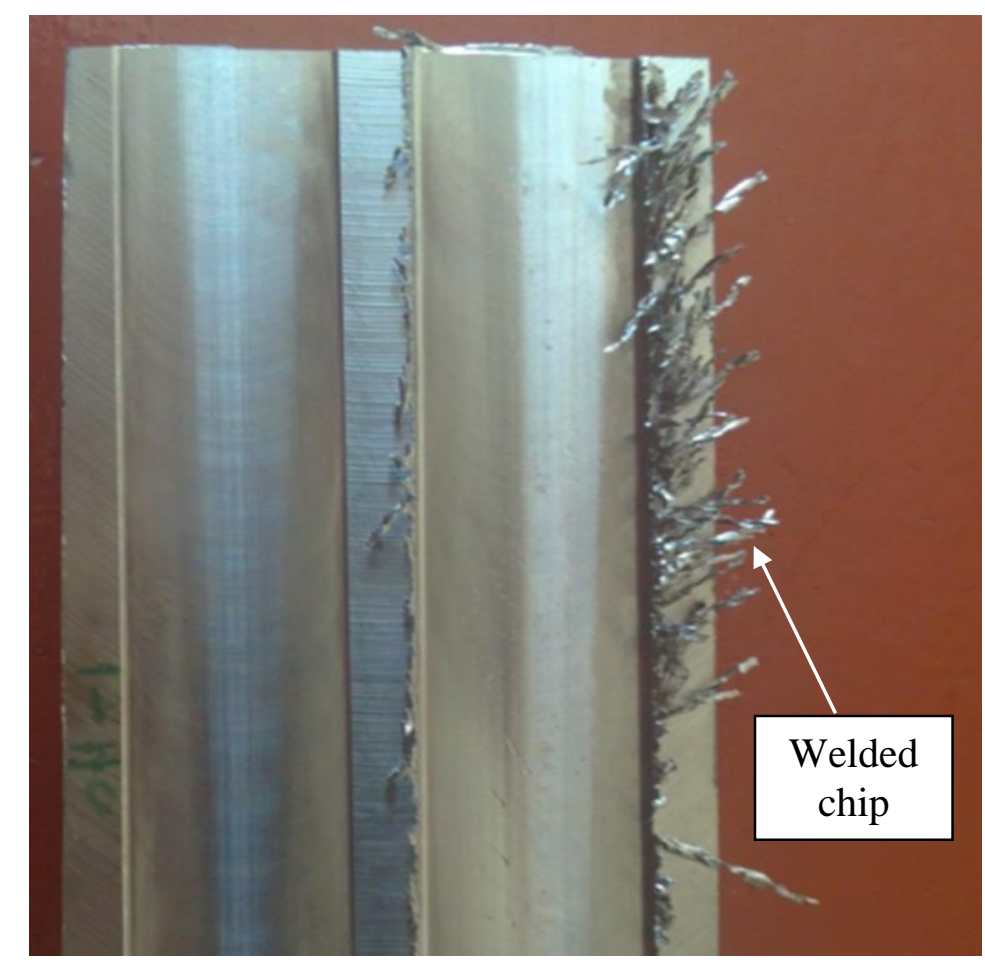

Figure 7.Welded chips with the slot machining of Hastelloy C-2000

\section{Optimization of the Cutting Force}

The main goal of the current work is to minimize the cutting force through an appropriate combination of variables, and by applying the optimization approach using the statistical analysis, it is possible to achieve this aim. Desirability functions would be used to convert each response and the weight would be able to define the desirability function shape for each of the responses. By using any weight from 0.1 to 10 for each of the responses, the target can be emphasized or de-emphasized. For example, a weight:

- less than one (minimum is 0.1 ) places less emphasis on the target

- equal to one places equal importance on the target and the bounds

- greater than one (maximum is 10) places more emphasis on the target.

The optimum value for cutting force is that which corresponds to the design variables based on Table 5. The validation test was performed based on the design variables and the percentage of error was calculated. The outcome that was achieved from the validation test gave a precise target for the optimization of the cutting force. 
Table 5. The optimum value for cutting force for coated and uncoated carbide

\begin{tabular}{ccccccc}
\hline $\begin{array}{c}\text { Cutting } \\
\text { insert }\end{array}$ & $\begin{array}{c}\text { Feed rate } \\
(\mathrm{mm} / \text { tooth })\end{array}$ & $\begin{array}{c}\text { Axial } \\
\text { depth }\end{array}$ & $\begin{array}{c}\text { Cutting } \\
\text { speed } \\
(\mathrm{m} / \mathrm{min})\end{array}$ & $\begin{array}{c}\text { Target } \\
(\mathrm{N})\end{array}$ & $\begin{array}{c}\text { Experimental } \\
(\mathrm{N})\end{array}$ & $\begin{array}{c}\text { Error } \\
(\%)\end{array}$ \\
\hline $\begin{array}{c}\text { Coated } \\
\text { carbide }\end{array}$ & 0.10 & 0.4 & 31 & 450 & 460 & 2.222 \\
$\begin{array}{c}\text { Uncoated } \\
\text { carbide }\end{array}$ & 0.10 & 0.4 & 31 & 550 & 563.4 & 2.444 \\
\hline
\end{tabular}

\section{CONCLUSIONS}

Based on the performance and test results of the various sets of experiments performed for analyzing the influence of cutting parameters on the machinability characteristics of Hastelloy C-2000, it can be concluded that cutting force is affected primarily by feed rate, followed by axial depth and cutting speed. As the cutting speed increases, the cutting force decreases. These influences on the cutting parameters are the result of the development of a response surface model for cutting force. There are two kinds of chips found as part of this study: Type I, the unstable chip, and type II, the critical chip. Chip formation is influenced by the cutting speed and because cutting temperature is related to cutting speed, the proper selection of cutting speed is essential.

\section{ACKNOWLEDGMENTS}

The authors are grateful to the Universiti Malaysia Pahang for financial support under Fundamental Research Grant Scheme (Project No. RDU110110).

\section{REFERENCES}

[1] Razak NH, Rahman MM, Kadirgama K. Experimental study on surface integrity in end milling of hastelloy c-2000 superalloy. International Journal of Automotive and Mechanical Engineering. 2014;9:1578-87.

[2] Sahaya Anand TJ. Nickel as an alternative automotive body materials. Journal of Mechanical Engineering and Sciences. 2012;2:187-97.

[3] Kadirgama K, Rahman MM, Ismail AR, Bakar RA. Finite element analysis of hastelloy c-22hs in end milling. Journal of Mechanical Engineering and Sciences. 2011;1:37-46.

[4] M'Saoubi R, Outeiro JC, Chandrasekaran H, Dillon Jr OW, Jawahir IS. A review of surface integrity in machining and its impact on functional performance and life of machined products. International Journal of Sustainable Manufacturing. 2008;1:203-36.

[5] Guo YB, Yen DW. A fem study on mechanisms of discontinuous chip formation in hard machining. Journal of Materials Processing Technology. 2004;155:13506.

[6] Razak N, Rahman M, Kadirgama K. Experimental study on surface integrity in end milling of hastelloy c-2000 superalloy. International Journal of Automotive and Mechanical Engineering. 2014;9:1578-87. 
[7] Razak NH, Rahman MM, Kadirgama K. Investigation of machined surface in endmilling operation of hastelloy c-2000 using uncoated-carbide insert. Advanced Science Letters. 2012;13:300-5.

[8] Razak NH, Rahman MM, Kadirgama K. Response surface design model to predict surface roughness when machining hastelloy c-2000 using uncoated carbide insert. IOP Conference Series: Materials Science and Engineering2012. p. 012022.

[9] Isik Y. Investigating the machinability of tool steels in turning operations. Materials \& Design. 2007;28:1417-24.

[10] Najiha M, Rahman M, Kadirgama K. Performance of water-based tio2 nanofluid during the minimum quantity lubrication machining of aluminium alloy, aa6061t6. Journal of Cleaner Production. 2016; In press.

[11] Yusoff AR, Mohamed Suffian MRZ, Taib MY. Literature review of optimization technique for chatter suppression in machining. Journal of Mechanical Engineering and Sciences. 2011;1:47-61.

[12] Khan MAR, Rahman MM, Kadirgama K, Maleque MA, Ishak M. Prediction of surface roughness of ti-6al-4v in electrical discharge machining: A regression model. Journal of Mechanical Engineering and Sciences. 2011;1:16-24.

[13] Najiha MS, Rahman MM, Kadirgama K. Minimum quantity lubrication: Quantifying non-deterministic component of sustainability index for machining operations. International Journal of Automotive and Mechanical Engineering. 2016;13:3190-200.

[14] Mohanty S, Routara BC. A review on machining of metal matrix composites using nanoparticle mixed dielectric in electro-discharge machining. International Journal of Automotive and Mechanical Engineering. 2016;13:3518-39.

[15] Najiha MS, Rahman MM, Kadirgama K. Machining performance of aluminum alloy 6061-t6 on surface finish using minimum quantity lubrication. International Journal of Automotive and Mechanical Engineering. 2015;11:2699-712.

[16] Rahman MM, Kadirgama K, Noor MM, Ramasamy D. Optimization of abrasive machining of ductile cast iron using tio2 nanoparticles: A multilayer perceptron approach. ARPN Journal of Engineering and Applied Sciences. 2016;11:2529-34.

[17] Muthusamy Y, Kadirgama K, Rahman MM, Ramasamy D, Sharma KV. Wear analysis when machining aisi 304 with ethylene glycol/tio2 nanoparticle-based coolant. International Journal of Advanced Manufacturing Technology. 2016;82:327-40.

[18] Najiha MS, Rahman MM, Kadirgama K. Experimental investigation and optimization of minimum quantity lubrication for machining of aa6061-t6. International Journal of Automotive and Mechanical Engineering. 2015;11:272237.

[19] Fang N, Wu Q. A comparative study of the cutting forces in high speed machining of ti-6al-4v and inconel 718 with a round cutting edge tool. Journal of Materials Processing Technology. 2009;209:4385-9.

[20] Li HZ, Zeng H, Chen XQ. An experimental study of tool wear and cutting force variation in the end milling of inconel 718 with coated carbide inserts. Journal of Materials Processing Technology. 2006;180:296-304.

[21] Krain HR, Sharman ARC, Ridgway K. Optimisation of tool life and productivity when end milling inconel 718tm. Journal of Materials Processing Technology. 2007;189:153-61. 
[22] Zhang S, Li JF, Wang YW. Tool life and cutting forces in end milling inconel 718 under dry and minimum quantity cooling lubrication cutting conditions. Journal of Cleaner Production. 2012;32:81-7.

[23] Astakhov VP. Tribology of metal cutting. Mechanical Tribology, New York: Marcel Dekker. 2004:307-46.

[24] Cristino VAM, Rosa PARC, Martins PAF. Tribology in metal cutting. Tribology for scientists and engineers: Springer; 2013. p. 677-728.

[25] Shih AJ, Luo J, Lewis MA, Strenkowski JS. Chip morphology and forces in end milling of elastomers. Journal of Manufacturing Science and Engineering. 2004;126:124-30.

[26] Nakayama K, Arai M. Comprehensive chip form classification based on the cutting mechanism. CIRP Annals-Manufacturing Technology. 1992;41:71-4.

[27] Outeiro JC, Pina JC, M'saoubi R, Pusavec F, Jawahir IS. Analysis of residual stresses induced by dry turning of difficult-to-machine materials. CIRP AnnalsManufacturing Technology. 2008;57:77-80.

[28] Devillez A, Le Coz G, Dominiak S, Dudzinski D. Dry machining of inconel 718, workpiece surface integrity. Journal of Materials Processing Technology. 2011;211:1590-8.

[29] Pusavec F, Hamdi H, Kopac J, Jawahir IS. Surface integrity in cryogenic machining of nickel based alloy-inconel 718. Journal of Materials Processing Technology. 2011;211:773-83.

[30] M'saoubi R, Outeiro JC, Changeux B, Lebrun JL, Dias AM. Residual stress analysis in orthogonal machining of standard and resulfurized aisi 3161 steels. Journal of Materials Processing Technology. 1999;96:225-33.

[31] Ezugwu EO, Wang ZM, Okeke CI. Tool life and surface integrity when machining inconel 718 with pvd-and cvd-coated tools. Tribology Transactions. 1999;42:35360 .

[32] Jindal PC, Santhanam AT, Schleinkofer U, Shuster AF. Performance of pvd tin, ticn, and tialn coated cemented carbide tools in turning. International Journal of Refractory Metals and Hard Materials. 1999;17:163-70.

[33] Hynes International. Http://www.Haynesintl.Com/. Retrived on 16 June 2017.

[34] Astakhov VP. Tribology of metal cutting: Elsevier; 2006.

[35] Aykut Ș, Bagci E, Kentli A, Yazıcıoğlu O. Experimental observation of tool wear, cutting forces and chip morphology in face milling of cobalt based super-alloy with physical vapour deposition coated and uncoated tool. Materials \& Design. 2007;28:1880-8.

[36] Kishawy HA, Elbestawi MA. Effects of process parameters on material side flow during hard turning. International Journal of Machine Tools and Manufacture. 1999;39:1017-30.

[37] Sreejith PS, Ngoi BKA. Dry machining: Machining of the future. Journal of Materials Processing Technology. 2000;101:287-91.

[38] Vyas A, Shaw MC. Mechanics of saw-tooth chip formation in metal cutting. Journal of Manufacturing Science and Engineering. 1999;121:163-72.

[39] Morehead MD, Huang Y, Luo J. Chip morphology characterization and modeling in machining hardened 52100 steels. Machining Science and Technology. 2007;11:335-54.

[40] Thakur DG, Ramamoorthy B, Vijayaraghavan L. Study on the machinability characteristics of superalloy inconel 718 during high speed turning. Materials \& Design. 2009;30:1718-25. 
[41] Thakur DG, Ramamoorthy B, Vijayaraghavan L. Machinability investigation of inconel 718 in high-speed turning. The International Journal of Advanced Manufacturing Technology. 2009;45:421-9.

[42] Davies MA, Burns TJ, Evans CJ. On the dynamics of chip formation in machining hard metals. CIRP Annals-Manufacturing Technology. 1997;46:25-30. 